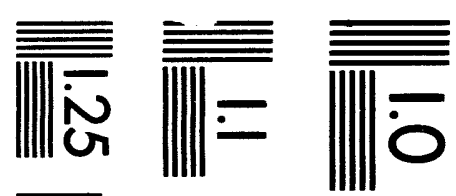

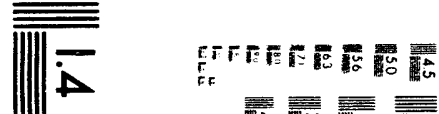

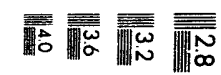

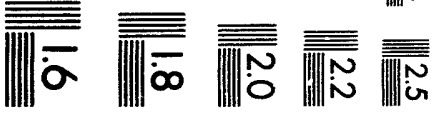




\title{
REDUCTION OF DEFECT FLUXES USING DUAL-ION-BEAM PROCESSING*
}

\author{
A. Iwase, ${ }^{* *}$ L. Rehn, and P. M. Baldo, P. R. Okamoto, H. Wiedersich and L. Funk \\ Materials Science Division \\ Argonne National Laboratory \\ Argonne, IL 60439
}

November 1993

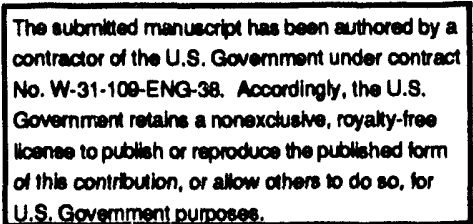

DISCLAIMER

\begin{abstract}
This report was prepared as an account of work sponsored by an agency of the United States Government. Neither the United States Government nor any agency thereof, nor any of their employees, makes any warranty, express or implied, or assumes any legal liability or responsibility for the accuracy, completeness, or usefulness of any information, apparatus, product, or process disclosed, or represents that its use would not infringe privately owned rights. Reference herein to any specific commercial product, process, or service by trade name, trademark, manufacturer, or otherwise does not necessarily constitute or imply its endorsement, recommendation, or favoring by the United States Government or any agency thereof. The views and opinions of authors expressed herein do not necessarily state or reflect those of the United States Government or any agency thereof.
\end{abstract}

To be presented at the 1993 Fall Meeting of the Materials Research Society, Boston, MA, November 29-December 3, 1993.

*Work supported by the U.S. Department of Energy, BES-Materials Sciences, under contract \#W-31-109-ENG-38.

**Permanent Address: Japan Atomic Energy Research Institute, Tokai-mura, Naka-gun Ibaraki, 319-11, Japan 


\section{REDUCTION OF DEFECT FLUXES USING DUALION-BEAM PROCESSING}

A. IWASE ${ }^{1,2}$, L. E. REHN ${ }^{1}$, P. M. BALDO ${ }^{1}$, P. R. OKAMOTO ${ }^{1}$, H. WIEDERSICH ${ }^{1}$ AND L. FUNK ${ }^{1}$

${ }^{1}$ Materials Science Division, Argonne National Laboratory, 9700 S. Cass Ave. Argonne IL 60439

2 Japan Atomic Energy Research Institute, Tokai-mura, Naka-gun, Ibaraki, 319-11, Japan

\section{ABSTRACT}

Radiation-induced segregation (RIS) in $\mathrm{Ni}-12.7 \% \mathrm{Si}$ and $\mathrm{Cu}-1 \% \mathrm{Au}$ alloys was studied using Rutherford backscattering spectroscopy during $\mathrm{He}$ and $\mathrm{Ne}$ irradiation at elevated temperatures. During single ion-beam irradiation with $1.5 \mathrm{MeV} \mathrm{He}$, strong RIS of Si toward the surface was observed in $\mathrm{Ni}$ $12.7 \% \mathrm{Si}$. Simultaneous irradiation with $400 \mathrm{keV} \mathrm{Ne}$ and $1.5 \mathrm{MeV} \mathrm{He}$ almost completely suppressed the Si segregation, even when the calculated damage production rate by $\mathrm{Ne}$ was only a few percent of that by $\mathrm{He}$ ions. A similar effect of dual-beam irradiation was observed in the $\mathrm{Cu}-1 \% \mathrm{Au}$ alloy, i.e., the rate of near surface $A u$ depletion was strongly reduced under simultaneous irradiation. The present result shows that dual-beam irradiation can be applied to control RIS and RED (Radiation Enhanced Diffusion) during ion beam processing.

\section{INTRODUCTION}

As shown by much work over the past two decades[1], significant nonequilibrium segregation of alloying elements has been observed in a number of alloys following irradiation at elevated temperatures. This Radiation-Induced Segregation (RIS) is caused by the interactions of radiation-produced defect fluxes with alloying elements. RIS may become a serious problem for ion beam processing at elevated temperatures, because it can cause composition changes in alloys during irradiation. In this paper, we demonstrate that simultaneous irradiation with $\mathrm{Ne}$ can strongly suppress the RIS by $\mathrm{He}$ irradiation in $\mathrm{Ni}-12.7 \% \mathrm{Si}$ and $\mathrm{Cu}-1 \%$ Au alloys.

\section{EXPERIMENTAL PROCEDURE}

$\mathrm{Ni}-12.7 \% \mathrm{Si}$ specimens were irradiated simultaneously with $1.5 \mathrm{MeV} \mathrm{He}$ and $400 \mathrm{keV} \mathrm{Ne}$ ions at $500{ }^{\circ} \mathrm{C}$. During irradiation, Rutherford backscattering (RBS) spectra from the He ions were acquired simultaneously every 10 minutes. Ion currents were kept constant(100 nA through a $1 \mathrm{~mm}$ diameter aperture for $\mathrm{He}$, and $1 \mathrm{nA}, 0.25 \mathrm{nA}$ and $0.1 \mathrm{nA}$ through a $3 \mathrm{~mm}$ diameter aperture for $\mathrm{Ne}$ ). Actual current densities, $\mathrm{j}$, and the calculated dpa (displacements per atom) rate, $\mathrm{K}^{\text {calc }}$, in the near surface region are listed in Table I. The dpa rate was calculated using the TRIM computer 
code[2] and a displacement threshold energy of $33 \mathrm{eV}$. In Table I, the ratios of calculated dpa rate by $\mathrm{Ne}$ to that by $\mathrm{He}$ are also listed. The geometry for the measurements is shown in the insets of Fig. 1. In this experiment, the He ion beam was used both for defect production and for RBS analysis. For comparison. RBS spectra were also measured for a specimen pre-irradiated with $\mathrm{Ne}$ ions. Similar simultaneous irradiation and RBS measurements were performed in $\mathrm{Cu}-1 \% \mathrm{Au}$ specimens at $400{ }^{\circ} \mathrm{C}$.

TABLE I. Irradiation parameters.

\begin{tabular}{lllll} 
Ion & $\mathrm{I}(\mathrm{nA})$ & $\mathrm{j}\left(\mathrm{nA} / \mathrm{cm}^{2}\right)$ & $\mathrm{K}^{\mathrm{calc}}(\mathrm{dpa} / \mathrm{s})$ & $\mathrm{K}^{\mathrm{calc}}(\mathrm{Ne}) / \mathrm{K}^{\mathrm{calc}}(\mathrm{He})$ \\
\hline $1.5 \mathrm{MeV} \mathrm{He}$ & 100 & $1.3 \times 10^{4}$ & $7.6 \times 10^{-5}$ & - \\
$400 \mathrm{keV} \mathrm{Ne}$ & 1 & 14 & $1.9 \times 10^{-5}$ & 0.25 \\
& 0.25 & 3.5 & $4.8 \times 10^{-6}$ & 0.063 \\
& 0.1 & 1.4 & $1.9 \times 10^{-6}$ & 0.025
\end{tabular}

\section{RESULTS AND DISCUSSION}

Figure 1(a) shows RBS spectra from a Ni-12.7\% Si specimen before and after irradiation with $1.5 \mathrm{MeV}$ He ions to a dose of $1.1 \times 10^{18} / \mathrm{cm}^{2}$ at $500{ }^{\circ} \mathrm{C}$. Reduction. in the Ni RBS yield near the Ni leading edge is clearly observed after irradiation. Previous TEM and RBS studies show that this reduction is attributed to a strong RIS of $\mathrm{Si}$ to the surface and the precipitation of $\gamma^{\prime}$ $\mathrm{Ni}_{3} \mathrm{Si}[1]$. The RIS is also observed as an increase in the Si yield at and just behind the Si edge. This segregation is caused by the existence of a persistent flux of defects to the surface and a preferential coupling of $\mathrm{Si}$ atoms to these defects. The amount of Si segregation (or the depletion of $\mathrm{Ni}$ ) near the surface can be readily determined from the difference between the RBS spectra for irradiated and unirradiated specimens. The change in area in the spectrum near the $\mathrm{Ni}$ edge, or the $\mathrm{Si}$ edge, is directly proportional to the amount of segregation.

Figures 1 (b) and 1(c) show the RBS spectra obtained after simultaneous $\mathrm{He}$ and Ne ion irradiation for 4 hours. RIS of Si to the surface is strongly suppressed by the simultaneous irradiation, even when the calculated dpa rate for $\mathrm{Ne}$ is only a few percent of that for the He ions. With increasing $\mathrm{Ne}$ beam current, the RIS decreases even further.

The suppression of RIS can be seen more clearly in Fig. 2. In this figure, the amount of segregation in $\mathrm{Ni}-12.7 \% \mathrm{Si}$ is plotted as a function of He dose for only $\mathrm{He}$ ion irradiation, and for simultaneous $\mathrm{He}$ and $\mathrm{Ne}$ irradiation. During only Fe ion irradiation, the amount of segregation increases with increasing He dose. During simultaneous irradiation, the segregation rate is much smaller than that during only He irradiation, becoming nearly zero for the conditions in Fig. 1(c). 

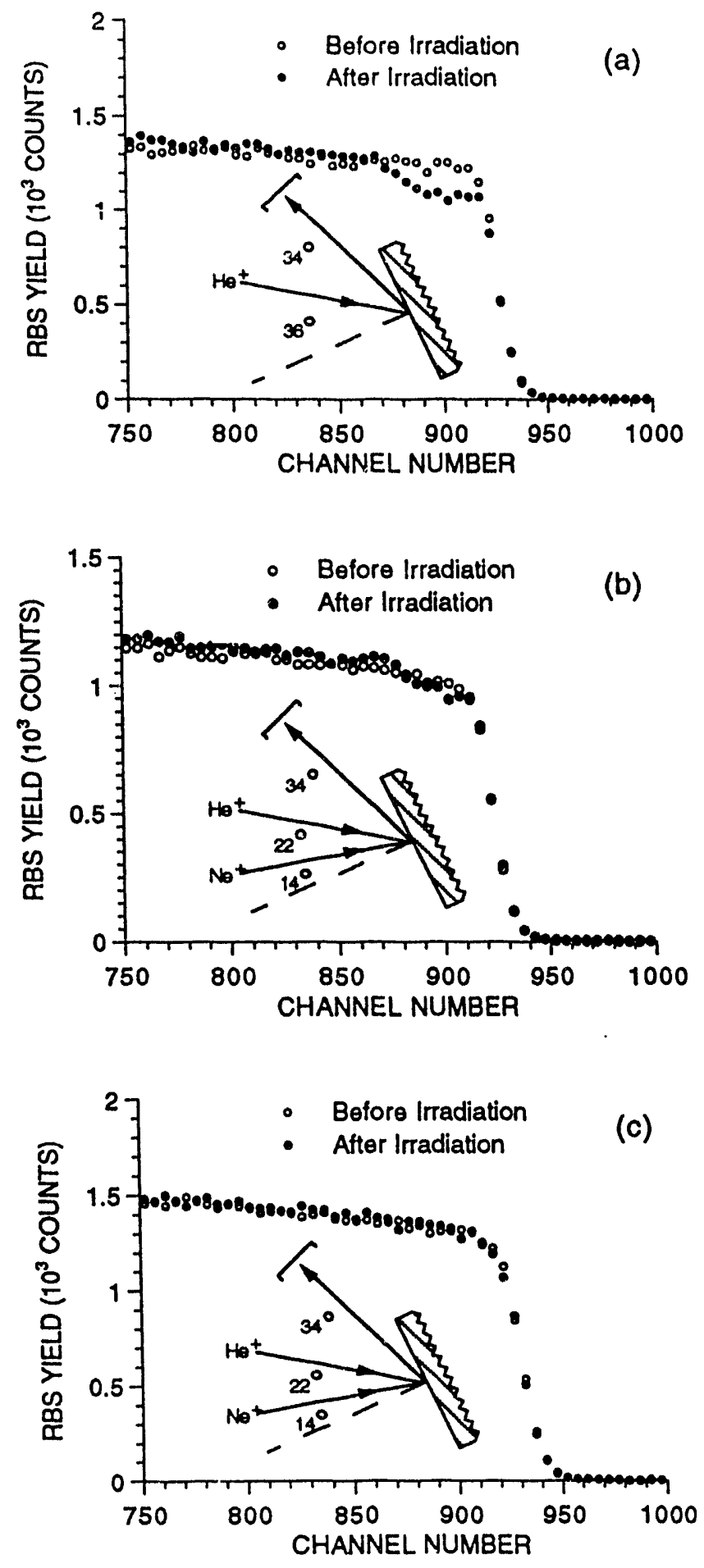

Fig. 1. RBS spectra for $1.5 \mathrm{MeV}^{4} \mathrm{He}$ ions incident on $\mathrm{Ni}-12.7 \% \mathrm{Si}$ before irradiation (open circles), and after (a) $1.5 \mathrm{MeV} \mathrm{He}$ irradiation, (b) simultaneous $1.5 \mathrm{MeV} \mathrm{He}$ and $400 \mathrm{keV}, 0.1 \mathrm{nA}$ Ne irradiation, and (c) simultaneous $1.5 \mathrm{MeV} \mathrm{He}$ and $400 \mathrm{keV}, 1 \mathrm{nA} \mathrm{Ne}$ irradiation (closed circles). Note the large drop in $\mathrm{Ni}$ yield near the $\mathrm{Ni}$ leading edge due to the segregation of Si toward the surface in (a). 


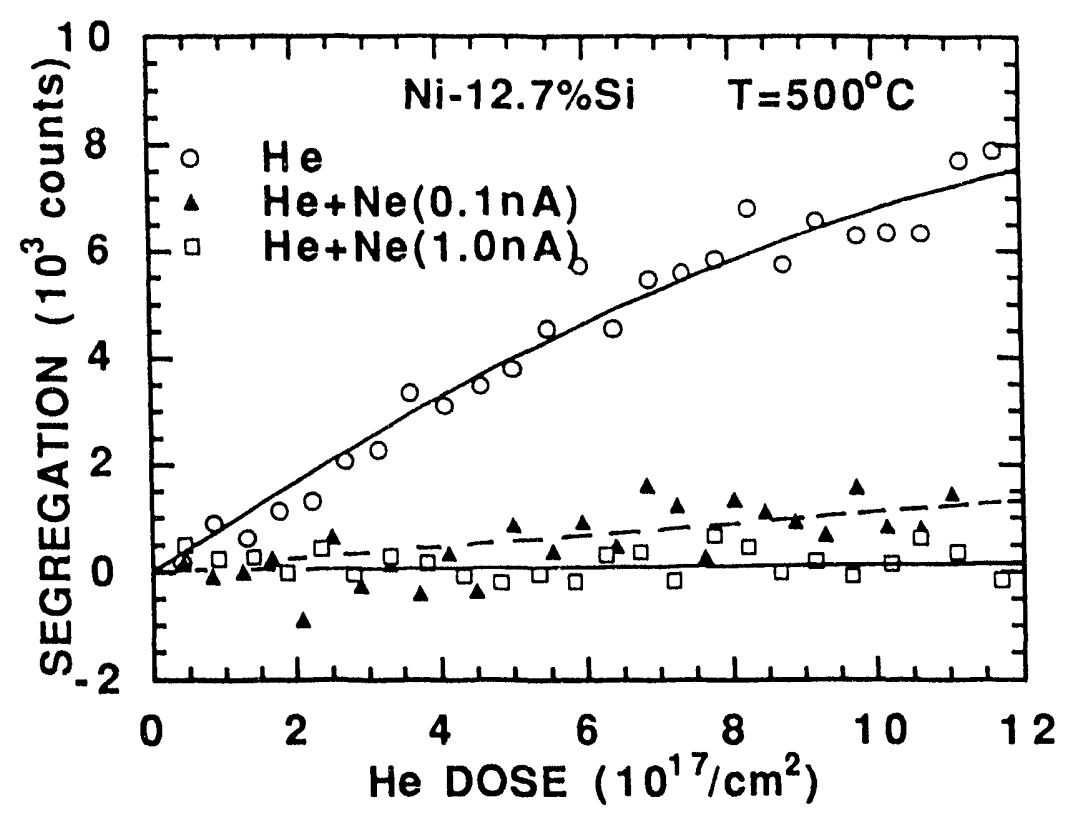

Fig. 2. Amount of near-surface segregation in $\mathrm{Ni}-12.7 \% \mathrm{Si}$ specimens during simultaneous $1.5 \mathrm{MeV} \mathrm{He}$ and $400 \mathrm{keV}$ Ne irradiation for two different $\mathrm{Ne}$ beam currents. For comparison, segregation for the He only irradiation (open circles) is also plotted.

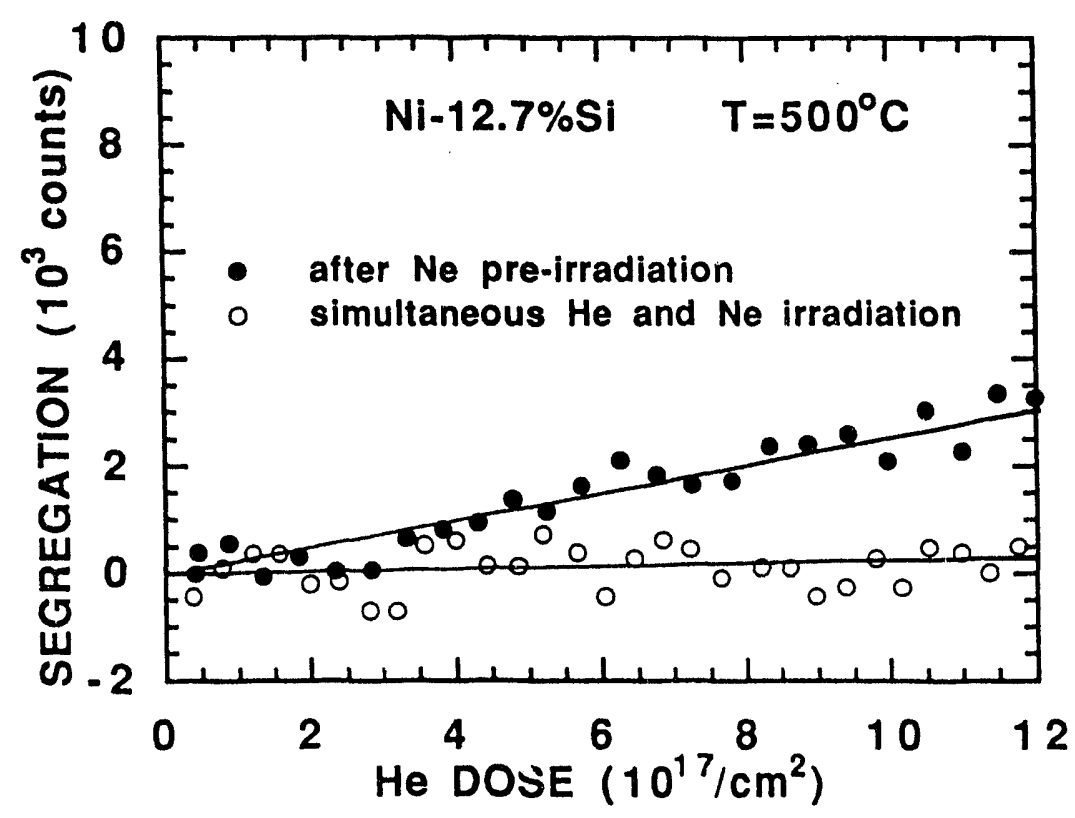

Fig. 3. Amount of near-surface segregation in $\mathrm{Ni}-12.7 \% \mathrm{Si}$ specimens measured during $1.5 \mathrm{MeV}$ He irradiation after pre-irradiation with $400 \mathrm{keV}$ $\mathrm{Ne}\left(1 \mathrm{nA}, 1\right.$ hour at $500^{\circ} \mathrm{C}$ ), and during simultaneous $1.5 \mathrm{MeV} \mathrm{He}$ and 400 $\mathrm{keV}, 0.25 \mathrm{nA} \mathrm{Ne}$ irradiation. 
To compare the effect of simultaneous irradiation with any preirradiation effect on RIS, the following experiment was performed. A $\mathrm{Ni}$ $12.7 \% \mathrm{Si}$ specimen was irradiated with $400 \mathrm{keV}$ Ne at $500{ }^{\circ} \mathrm{C}$ to a dose of $3.2 \times 10^{14} \mathrm{~cm}^{-2}$. The Ne beam current vas $1 \mathrm{nA}$ through the $3 \mathrm{~mm}$ diameter aperture, and the irradiation time was 1 hour; the result is shown in Fig. 3. In the figure, the amount of segregation during simultaneous $\mathrm{He}$ and $0.25 \mathrm{nA}$ $\mathrm{Ne}$ irradiation for 4 hours is also shown. Comparison of the two experimental curves in Fig. 3 shows clearly that the simultaneous $\mathrm{He}$ and $\mathrm{Ne}$ irradiation is far more effective than pre-irradiation with $\mathrm{Ne}$ for suppressing segregation. The total dose of Ne was the same in both experiments, i. e. $3.2 \times 10^{14} \mathrm{~cm}^{-2}$.

To test the universality of the suppression effect, similar measurements were made for $\mathrm{Cu}-1 \% \mathrm{Au}$ at $400{ }^{\circ} \mathrm{C}$, with $\mathrm{He}$ and Ne currents of $100 \mathrm{nA}$ through the $1 \mathrm{~mm}$ diameter aperture, and $1 \mathrm{nA}$ through the $3 \mathrm{~mm}$ diameter aperture, respectively. In this alloy, RIS causes a depletion of Au atoms near the surface[3]. Figure 4 shows that the strong suppression effect is also observed in $\mathrm{Cu}-1 \% \mathrm{Au}$. although these two alloy systems have quite different defect properties.

As RIS is driven by defect fluxes to the surface, our experimental results imply that simultaneous Ne irradiation strongly reduces these defect fluxes. $\mathrm{Ne}$ irradiation can affect the production of freely migrating defects, and the concentration and structure of internal sinks. A reduction of the production rate of freely migrating defects or an increase in sink concentration would both reduce the defect flux. The mechanism of defect flux reduction therefore remains uncertain. In any case, simultaneous $\mathrm{Ne}$ irradiation suppresses RIS effectively even for very small currents, and thus may provide a useful method for controlling RIS and RED during ion beam processing.

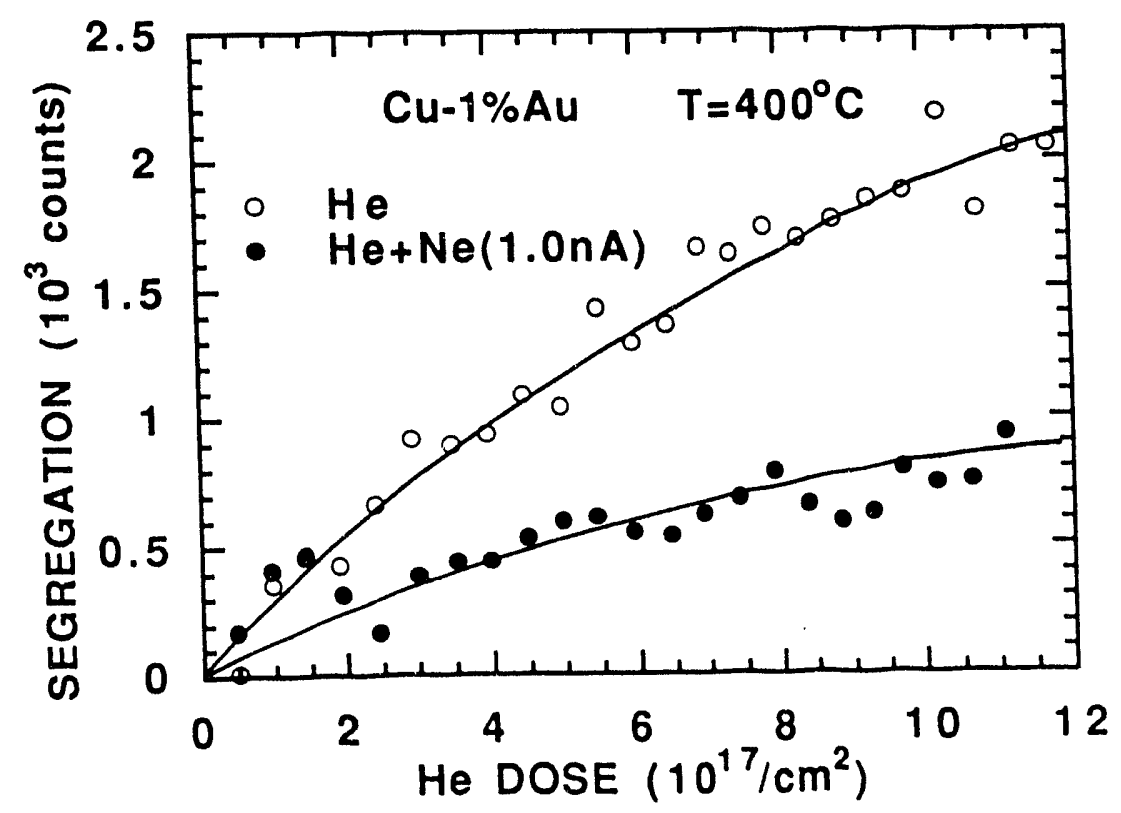

Fig. 4. Amount of near-surface segregation in $\mathrm{Cu}-1 \%$ Au specimens during only $\mathrm{He}$ ion irradiation, and during simultaneous $1.5 \mathrm{MeV}$ He and $400 \mathrm{keV}, 1$ $\mathrm{nA} \mathrm{Ne}$ ion irradiation. 


\section{SUMMARY}

Radiation induced segregation (RIS) in $\mathrm{Ni}-12.7 \% \mathrm{Si}$ and $\mathrm{Cu}-1 \% \mathrm{Au}$ alloys during $1.5 \mathrm{MeV} \mathrm{He}$ and $400 \mathrm{keV} \mathrm{Ne}$ ion irradiation was measured at elevated temperatures using Rutherford backscattering spectroscopy.

In both alloys, RIS to the surface was strongly suppressed during simultaneous irradiation with ion beams of $1.5 \mathrm{MeV}$ He and $400 \mathrm{keV} \mathrm{Ne}$. The suppression effect of the simultaneous irradiation is much stronger than the effect of pre-irradiation.

\section{ACKNOWLEDGMENT}

We thank B. Kestel for preparing the specimens. This work was supported by the U. S. Department of Energy, BES-Materials Science under contract W-31-109-Eng-38.

\section{REFERENCES}

1. L. E. Rehn and P. R. Okamoto, in Phase Transformations During Irradiation. edited by F. V. Nolfi, Jr., (Applied Science Publishers, London, 1982) p. 247.

2. J. P. Biersack and L. G. Haggmark, Nucl. Instrum. Methods 174, 257 (1980).

3. T. Hashimoto, L. E. Rehn and P. R. Okamoto, Phys. Rev. B38, 868 (1988). 

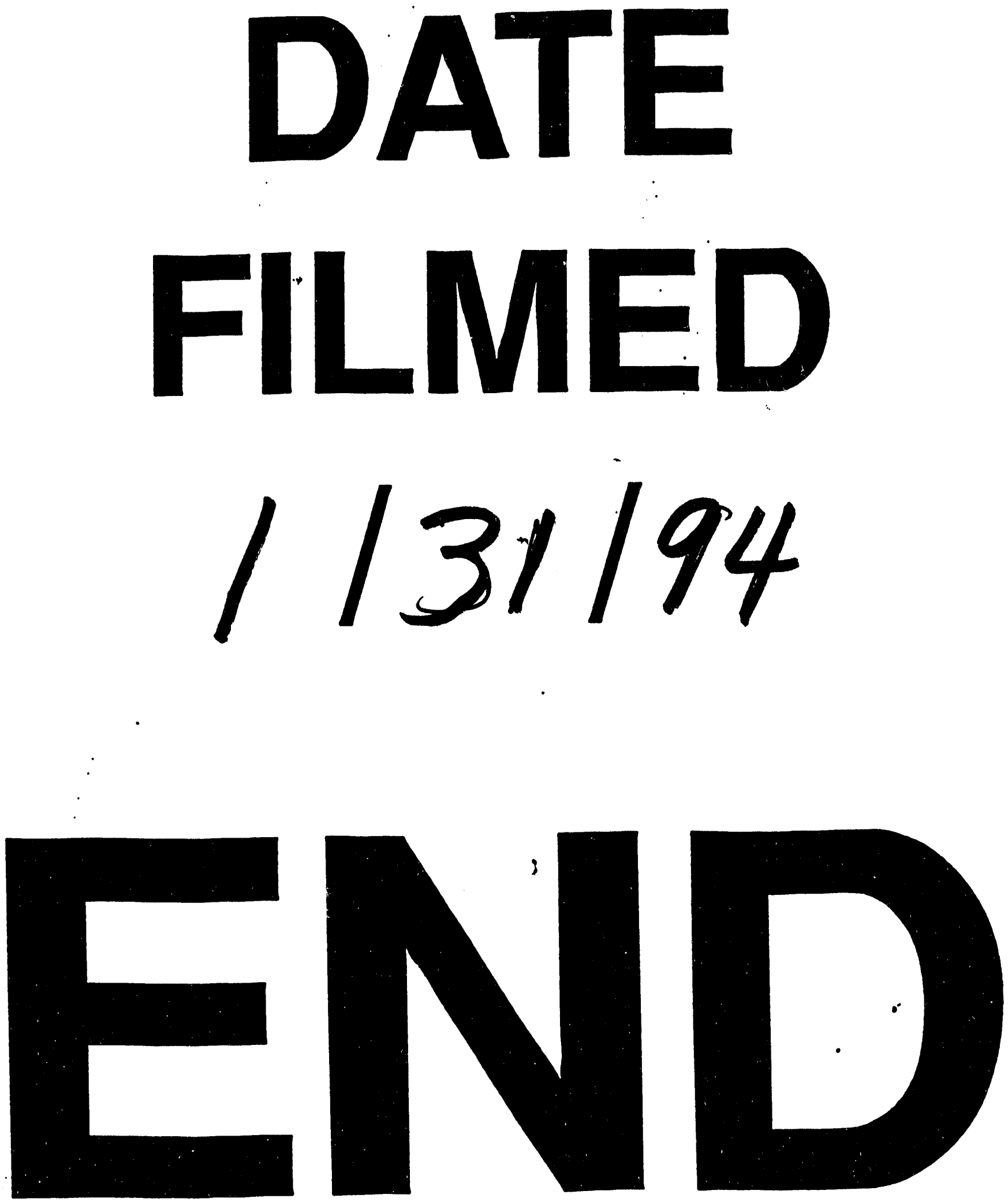
